Journal of Social Sciences 8 (3): 467-471, 2012

ISSN 1549-3652

(C) 2012 Science Publications

\title{
A Teaching Method to Develop a Critical Thinking of the Students of the General Education Ecclesiastical School
}

\author{
Phrakhruvisitpattanaporn, Saner Piromjitrapong and Saman Asavabhumi \\ Graduate School of Ubonratchathani, \\ Rajabhat University, Ubonratchathani Province, 34000, Thailand
}

\begin{abstract}
Problem statement: The objectives of the research were to study (1) the teaching method to develop a critical thinking of the students of the General Education Ecclesiastical School, (2) the effectiveness of the teaching method to develop a critical thinking of the students of the General Education Ecclesiastical School. Approach: The populations were the students of 35 general education ecclesiastical schools in the provinces of Ubon Ratchathani, Yasothon and Amnat Charoen. The samples of 43 students of Kittiyanwittaya were selected by a purposive sampling. The research instruments were a lesson plan on Buddhist Doctrine, a format to assess an ability of a critical thinking and a test on an achievement. Statistics used was t-test. Learning activity consisted of five components: (1) ability to define the problems, (2) ability to choose an information relevant to the problems, (3) ability to be aware of the preliminary agreement, (4) ability to determine and choose hypothesis and (5) ability to conclude reasonably. Results: As for the effectiveness of the teaching method in study, there were two parts considered: (1) the effectiveness of the teaching method to develop a critical thinking of the students was found at $81.0 / 84.0$, which was in conformity with the $80 / 80$ criterion; (2) as regards achievement of the teaching and learning based on the teaching method under study, it was found that the achievement after using of the method was higher with a statistical significance of 0.01 . Conclusion: The significance of the research is the effectiveness of the teaching method to develop a critical thinking of the students. The teaching method had the effectiveness at 81.0/84.0. and the achievement of the teaching after used the teaching method the average score was equivalent 42.09 . The learning achievement was statically higher than that before using the method at 0.01 level of significance.
\end{abstract}

Key words: Teaching method, research and development, critical thinking, general education ecclesiastical school

\section{INTRODUCTION}

Development of human thought is gaining its currency. The aim of the educational quality assurance was to enable the learners to think, analyze, create and reflect. However, it was found that the achievement in the learners' ability to think, analyze, synthesize and reflect was low or $18.74 \%$. The percentage of learners to classify and compare information was only $26.24 \%$. The percentage of learners to initiate, predict and determine the target was $36.75 \%$. The root cause could be that teachers did not realize the way to develop the thinking process. Most of them based the teaching process on the subject matter; as a result, it turned out that the learners who were traditionally taught were unable to deal with the problems in a real world.

Critical thinking is a rational and reflective mental act on the issues, arguments with utter prudence on the basis of knowledge, ideas and experiences in order to reach a reasonable conclusion. A critical thinking is an advanced level of exercising a mental activity based on the rational principles. It is a crucial tool in learning and leading a valuable life. Several of scholars commonly view that a critical thinking is essential to generate a maximum benefits to learners. It can be used in living a life in the present day world in a creative manner (ONEC, 1999). More importantly, a critical thinking plays a vital role to enable a person to think creatively, act reasonably and solve problems more effectively.

An ecclesiastical study combined with a formal education is conducted for the Monastic Order. The educational pattern is modeled on the curriculum designated by the Ministry of Education. This type of education is meant for both Buddhist monks and novices who are expected to know both secular and religious affairs. It is expected that well equipped with

Corresponding Author: Phrakhruvisitpattanaporn, Graduate School of Ubonratchathani Rajabhat University,

Ubonratchathani Province, 34000, Thailand Tel: ++66 45353007 Fax+66 45311465 
this type of education, they are able to adjust well to the changing social conditions. In the curriculum are included the courses that offer the following: Pali language, Buddhist Doctrine and Discipline, Religious Traditions, Thai, English, Social Studies, Mathematics, Science, Arts, Vocation and Technology.

The researcher is interested to study a teaching method unique to develop a critical thinking for the youths studying at the Ecclesiastical School by organizing the learning activities based on Bloom's taxonomy of cognitive domain. The teaching method for developing a critical thinking is constructed from exploring the problems faced at the Ecclesiastical School. The teaching pattern constructed contains the content on the Buddhist Doctrine of the Three Jewels and the Four Noble Truths. The teaching pattern is designed by taking into account the learners' age and social conditions. The expected benefits will be major guidelines in the process of developing and enhancing a critical thinking.

\section{MATERIALS AND METHODS}

The study was a type of Research and Development (R\&D). The populations were 35 Ecclesiastical Schools in the provinces of Ubon Ratchathani, Yasothon and Amnat Charoen. The samples groups were 43 Grade seven students of Kittayan Ecclesiastical School . The study was conducted by one group, pre-test and post-test design. The research duration was 12 months from December of 2010 to December of 2011.

\section{RESULTS}

The research findings were as follows:

- The teaching approach to train a critical thinking consisted of four components: (1) the principles, (2) the objectives, (3) learning and teaching activities, (4) instructional evaluation of the teaching method: in the process there were three main parts, that is, introduction, presentation and conclusion. In planning the lessons, there were five components for a critical thinking: (1) ability to define the problem, (2) ability to choose the information concerning the problems, (3) ability of being aware of the preliminary agreement, (4) ability to determine and choose a hypothesis and (5) ability to reasonably draw a conclusion

- Considering the effectiveness of the teaching method according to $80 / 80$ criterion, the following were found:
- The researcher evaluated the teaching method by using assignments, group behavior, the quiz and learning achievement tests. After the evaluation process, the researcher summarized the efficacy of the teaching method. The total number of students had got the score of 843.3 out of 1,050 , which accounted for $81.0 \%$. The evaluation after the used of the teaching method in question found that the average score of the students was 42.0 out of 50 representing $85.0 \%$. Based on the findings, it could be concluded that the teaching method to develop a critical thinking was 81.0/84.0, which was in line with the $80 / 80$ criterion

- As for the comparison of the learning achievement of the subjects in study, it was found that the average score of the students before the use of the teaching method to develop a critical thinking was equivalent to 28.23 and the average score after the use of the teaching method was equivalent to 42.09 . It indicated that grade seven students who learned by the teaching method to develop a critical thinking had a higher learning achievement with a statistically significant difference of 0.01

\section{DISCUSSION}

Discussion of the results can be based on the research hypothesis.

The teaching method to develop a critical thinking after being used proved a suitable one to be used to develop an ability to critically think in five aspects of the subjects who studied in the Ecclesiastical School.

Ability to define or know the problems. The learners were able to analyze the issues or the given situation and identify the key issues correctly. The teaching method in use was in conformity with the curriculum of the basic education with the aim for humans to be good, wise and capable. In addition, it could increase the learners' potential. The learners were able to live with others happily and engaged in the occupation of their choice as per their interest and ability.

Ability to choose information concerning the problems. The learners could decide which information was essential and relevant to the solution of the problems. This particular aspect was in line with B.F. Skinner's operant conditioning theory. According to the theory, learners get reinforcement. The theory application can provide great reinforcement for learners.

Ability of being aware of the primary agreement means the capacity to distinguish the problems and 


\section{J. Social Sci., 8 (3): 467-471, 2012}

identify the differences. The ability was in congruence with the teaching approach of Joyce et al. (2008). Joyce and Weil had proposed four groups of the teaching approaches: (1) The information processing family in which emphasis is placed on finding and processing information; as a result, learners could develop ideas and build the concept. In this type, some form places a emphasis for learners to build a concept and test hypothesis. Some emphasizes a development of a creative idea; some aims at promoting intelligence in general. (2) The social family focuses on learners to build a relationship with others and recognize interpersonal differences. It also emphasizes the reconciliation in solving the problems and participation. (3) The personal family aims to develop a person, attitude and values so that a person is in a better position to understand himself/herself and more responsible for one's own acts. (4) The behavioral system family focuses on the learners' behavior and practical skills. The theory belonging to the group is a social learning theory known as behavior modification and behavior therapy.

Ability to determine and choose a hypothesis it is the ability to choose a hypothesis from a given statement or situation in a reasonable manner. The aspect is in accordance with Piaget's concept on intellectual development that a child's intellectual development grows gradually. It is important for a teacher to follow a child's three stages of development. The first stage is concerned with sensory contact for learning ( $0-2$ years); the second stage is a period prior to the brain development (2-7 years), which can be subdivided into two: one is a child learns by imitating from what it sees and is familiar and the other is about developing a comparative concept about the size and quantity; the third stage is when a child develops ability to think (7-16 years). This stage can be divided into two levels: one is an idea about the link between the abstract and the concrete, the other is an ability to use the idea in abstract.

Ability to conclude rationally it is the ability to choose something to deal with the problems reasonably, to realize the cause and effects when it comes to making a decision. Given a teaching method used at the Ecclesiastical school under study, it was found that the teaching approach was in congruence with Bloom's taxonomy of cognitive domain in that changes in cognition, thinking and intellectual acts may affect behaviors. Thinking is the ability of human brain that can interpret the symbolic meaning in both the concrete and abstract. Thinking can vary in types from simple type like creative thinking to insight.
It can be said that the teaching approach to develop a critical thinking can be applied to all types of activities. Learners can make use of a well trained thinking skill in their life in the present or in the time to come. The concept was in line with Ennis (1990) idea that proposed that a critical thinking should be taught separately from what was normally taught based on the curriculum. According to Ennis, the main aim of teaching was teaching a learner to critically reflect on the content outside the school class. However, sometimes teaching how to critically think might require a content.

The present study was in congruence with the study by Browne and Freeman (2000) who conducted a research to synthesize the key components of a classroom's learning and teaching activity to help develop a critical thinking of students. The study found that for a critical thinking to develop there were four elements: (1) frequency of the questions (2) atmosphere favorable for argument (3) cooperative quest for information (4) encouragement for students to learn by themselves.

The discussion was in line with the study conducted by Al-Edwan and Al-Edwan (2011) who used the training program based on cognitive research trust strategies to develop seventh grade students' critical thinking in History Course. The result showed that there are statistical differences in seventh grade student's critical thinking for history course related to teaching methodology and for the way of the training program which is based on CoRT strategies.

The present study was in congruence with the study by Buntod et al. (2010) who conducted a research to find the effects of learning environmental education on science process skill and critical thinnking of Mathayomsuksa 3 students with different learning achievements. The study was found the 5 E-learning cycle which met cognitive techniques could develop efficient learning achievement, basic science process skills and critical thinking of the students. The teachers should be encouraged and supported to implement this approach in teaching and learning environment education in all grade levels.

By the way, the discussion was in line with the study conducted by Al-Edwan and Al-Edwan (2011) who used the training program based on cognitive research trust strategies to develop seventh grade students' critical thinking in History Course. The result showed that there are statistical differences in seventh grade student's critical thinking fro history course related to teaching methodology and for the way of the training program which is based on CoRT strategies. 
Sakat et al. (2012) who conducted a research about Education technology media method in teaching and learning progress. The study showed that the Computer usage can stimulate effective learning and improve the performance of Jawi education, enhancing the high level of interactivity among students.

Misron et al. (2011) studied about teaching the indigenous students by using the courseware based on theory of multiple intelligence. It was found that the indigenous children were able to accept the newlyintroduced courseware-assisted teaching and learning which includes the eight types of intelligences. This could be seen in their attendance record and achievement improvement.

According to Muthusamy et al. (2011), she studied about the effects of teaching literature on culture learning in the language classroom. It revealed that the cultural understanding can be taught through literature in a language classroom and it is a valuable instructional medium in the learning of culture.

In addition, the teaching approach is in conformity with that of Dressel and Mayhew (1957) who proposed that a critical thinking process consisted of (1) ability to define the problem, (2) ability to choose the information relevant to the problems, (3) ability to state a preliminary agreement, (4) ability to choose a hypothesis and (5) ability to conclude reasonably.

\section{CONCLUSION}

The objectives of the research were to (1) study the teaching pattern/ approach to develop a critical thinking of the students of the Ecclesiastical School and (2) study the effectiveness the teaching approach to develop a critical thinking. The research methodology was a research and development. The populations were the students of 35 Ecclesiastical Schools in the provinces of Ubon Ratchathani, Yasothon and Amnat Charoen. The samples were 43 students of Kittiyanvidaya School in Ubon Ratchathani, selected by a purpose sampling. The research instruments were 1 . The lesson plans on how to develop a critical thinking 2. A test for a critical thinking, 3. A test of learning achievement. Statistics used in the research was t-test.

The research findings were (1) the teaching approach to develop a critical thinking had three important parts : introduction, practice and conclusion. There were five components leading to a critical thinking (1) ability to define the problems, (2) ability to choose the information relevant to the problems, (3) ability to know the primary agreement, (4) ability to determine and choose the hypothesis and (5) ability to conclude reasonably. (2) As regards the effectiveness of the teaching approach to develop a critical thinking, there were two parts: (1) the effectiveness was found at $81.0 / 84.0$, which was in line with $80 / 80$ criterion used to measure the effectiveness of the teaching method; (2) as for the learning achievement of the teaching method to develop a critical thinking, it was found that with the scores obtained before and after the use of the teaching method in study compared, the pre-test scores wee equivalent to 28.23 and the post-test scores were equivalent to 42.09. The result showed that the achievement of the post-test was higher than that of the pre-test with a statistical significance of .01 .

\section{ACKNOWLEDGEMENT}

The researcher are grateful to the Ubonratchathani Rajabhat University and all of the instructors of the Department of Ph.D. (Regional Development Strategies), Graduate School of Ubonratchathani Rajabhat University for valuable services rendered in the course of this study. And thank you for all whom cannot be named at all.

\section{REFERENCES}

Al-Edwan, Z.S.M. and Z.S.M. Al-Edwan, 2011. The effectiveness of a training program based on cognitive research trust strategies to develop seventh grade students critical thinking in history course. J. Soc. Sci., 7: 436-442. DOI: 10.3844/jssp.2011.436.442

Browne, M.N. and K. Freeman, 2000. Distinguishing features of critical thinking classrooms. Teach. Higher Educ. 5: 302-309.

Buntod, P.C., P. Sucksrigam and A. Singseevo, 2010. Effects of learning environment education on science process skills and critical thinking of mathayomsuksa 3 students with different learning achievements. J. Soc. Sci., 6: 60-63. DOI: 10.3844/jssp.2010.60.63

Dressel, P.L. and L.B. Mayhew, 1957. General Education: Explorations in Evaluation: The Final Report of the Cooperative Study of Evaluation in General Education of the American Council on Education. 1st Edn., American Council on Education, Washington, D.C., pp: 302.

Ennis, R.H., 1990. The extent to which critical thinking is subject-specific: Further clarification. Educ. Res., 19 : 13-16. DOI: 10.3102/0013189X019004013

Joyce, B.R., M. Weil and E. Calhoun, 2008. Models of Teaching. 8th Edn., Allyn and Bacon, Boston, ISBN: 10- 0205593453, pp: 558. 
Misron, M.M., Z.A. Shaffiei, S.A. Suhadak and A.A. Mutalib, 2011. Teaching the indigenous students with courseware based on theory of multiple intelligences. Am. J. Eng. Biol. Sci., 3: 525-533. DOI: 10.3844/ajebasp.2011.525.533

Muthusamy, C., R. Marimuthu and S. Elangkeeran, 2011. Effects of teaching literature on culture learning in the language classroom. Am. J. Applied Sci., 8: 789-795. DOI: 10.3844/ajassp.2011.789.795
ONEC, 1999. National Education Act of B.E. 2542 (1999). Office of the National Education Commission, Bangkok.

Sakat, A.A., M.Z.M. Zin, R. Muhamad, A. Ahmad and N.A. Ahmad et al., 2012. Educational teachnology media method in teaching and learning progress. Am. J. Applied Sci., 9: 874-878. DOI: 10.3844/ajassp.2012.874.878 